Anales de Geografía de la Universidad Complutense ISSN: 0211-9803

http://dx.doi.org/10.5209/rev_AGUC.2016.v36.n1.52718

\title{
Turismo en Albarracín y Comarca. Acción pública local y dinámica reciente en clave de desarrollo turístico sostenible
}

\author{
Claudia Yubero Bernabé1; María García Hernández² \\ Recibido: 11 de enero del 2016 / Enviado a evaluar: 23 de enero del 2016 / Aceptado: 3 de mayo del 2016
}

Resumen. Los destinos turísticos españoles en medio rural se han ido configurando durante más de dos décadas de implementación de diversos instrumentos recogidos principalmente por las políticas turística y de desarrollo rural, que difunden un discurso y unos objetivos complementarios en teoría, pero contrapuestos tras su aplicación. De la tensión producida por esta intervención se configuran dos tipos de destino en la comarca de la Sierra de Albarracín (Teruel) cuya sostenibilidad está comprometida: el conjunto histórico de Albarracín como un destino consolidado de turismo cultural de base patrimonial y la Sierra como un destino incipiente de turismo rural genérico. Se argumenta cómo el despliegue de la acción pública local origina un territorio fragmentado en dos modelos de gestión y de desarrollo turístico. La cooperación se presenta como un elemento clave para el necesario replanteamiento del desarrollo turístico de la comarca.

Palabras clave: Políticas públicas; acción local; turismo en medio rural; dinamización cultural; cooperación.

\section{[en] Tourism in Albarracín and Region. Local Public Action and dynamics in recent key sustainable tourism development}

Abstract. Spanish tourist destinations in rural areas have been established over more than two decades of implementation of various public policy instruments (mainly tourism and rural development policies). These convey complementary objectives in theory but provoke distant results in practice. The intervention of these instruments produces in the region of Sierra de Albarracín (Teruel) two types of destination whose sustainability is committed: the historical urban site of Albarracín as a consolidated cultural tourism destination based on heritage and the Sierra as a generic and incipient destination of rural tourism. It is discussed how the deployment of the local public action causes a fragmented territory in two models of management and tourism development. Cooperation is presented as a key element for the necessary rethinking of tourism development in the region.

Key words: Public policies; local action; tourism in rural areas; cultural dynamization; cooperation.

1 Unidad de Investigación del Departamento de Geografía Huamana. Universidad Complutense de Madrid.

Grupo de Investigación “Turismo, Patrimonio y Desarrollo”. E-mail: claudiayebero@ucm.es

2 Departamento de Geografía Huamana. Universidad Complutense de Madrid.

Grupo de Investigación “Turismo, Patrimonio y Desarrollo”.

E-mail: mgarciah@ucm.es 


\title{
[fr] Tourisme Albarracin et Shire. Action publique et dynamique récente locales dans le développement clé du tourisme durable
}

\begin{abstract}
Résumé. Les destinations touristiques dans les zones rurales espagnoles ont été façonnées depuis plus de deux décennies de mise en œuvre des différents instruments recueillis principalement par les politiques publiques du tourisme et du développement rural. Diffusant un discours et des objectifs complémentaires en théorie, ces instruments ont des effets divergents après leur application. La tension produite par cette intervention dans la région de la Sierra de Albarracín (Teruel) a façonné deux types de destination dont la durabilité est questionnée: l'ensemble historique de Albarracín en tant que destination touristique culturelle consolidée de base patrimoniale et la Sierra comme destination initiale de tourisme rural générique. Il est expliqué comment le déploiement de l'action publique locale provoque un territoire fragmenté en deux modèles de gestion et de développement du tourisme. La coopération est présentée comme clé de lecture afin de repenser le développement du tourisme dans la région.
\end{abstract}

Mots clés: Politiques publiques; action locale; tourisme en milieu rural; dynamisation culturelle; coopération.

Cómo citar. Yubero Bernabé, C. y García Hernández, M (2016): Turismo en Albarracín y Comarca. Acción pública local y dinámica reciente en clave de desarrollo turístico sostenible. Anales de Geografía de la Universidad Complutense, 36(1), 173-194.

Sumario. 1. Introducción. 2. Turismo y desarrollo en el medio rural: estado de la cuestión. 2.1.El turismo como estrategia de la Política de Desarrollo Rural Europea en España. 2.2. Turismo rural y Política Turística en España. 2.3. Turismo rural: ¿una modalidad turística sostenible? 3. El turismo en Albarracín y Comarca. 3.1. Instrumentos y agentes del desarrollo turístico de la Sierra de Albarracín. 3.2. Desarrollo turístico reciente. 4. Discusión y conclusiones. 5. Bibliografía y fuentes de información.

\section{Introducción}

La extensión del turismo en el territorio rural español, así como la continuidad del tema en los debates científicos sobre turismo y territorio y la permanencia de su fomento mediante diversos instrumentos de políticas públicas durante más de tres décadas (1985-2015), evidencian la vigencia en los discursos de una hipótesis, más o menos matizada, que lo coloca como alternativa económica viable y sostenible para el desarrollo de estos territorios. Todo ello, a pesar de que en la mayoría de los casos los espacios rurales españoles se configuran como espacios donde se produce y consume turismo, alejados de su condición ideal de destinos sostenibles en entornos competitivos (Martín y Martin, 2014).

El turismo se ha configurado a nivel de discurso (político, académico y profesional) como un vector de desarrollo y diversificación económica para zonas rurales europeas aquejadas de problemas crónicos de despoblamiento y crisis de las actividades productivas tradicionales, y como tal se ha instrumentalizado en las políticas de desarrollo rural acometidas en los últimos treinta años. De forma paralela, en España, la administración turística ha venido apostando desde los años 90 por el desarrollo del turismo rural en tanto que modalidad emergente que converge con otras modalidades de turismo interior (turismo urbano, turismo cultural, turismo idiomático, ecoturismo, turismo de salud,...) en un intento por diversificar el producto turístico español, extender la huella turística a destinos incipientes y sortear la supuesta crisis del "sol y 
playa”. En este contexto, se desenvuelven las iniciativas recientes de turismo rural en España, que si bien se han venido presentando como una oportunidad de desarrollo con grandes posibilidades, dejan no pocos interrogantes sobre los resultados obtenidos, tanto en relación a los objetivos de la política de desarrollo rural como a los objetivos de la política turística (López Palomeque, 2008).

En este trabajo se presenta una investigación sobre la Sierra de Albarracín (escenario de recepción de fondos públicos desde 1996) al objeto de evaluar los resultados de aplicación de diferentes instrumentos de fomento del turismo en el medio rural. Se parte de la hipótesis de que existe una divergencia evidente entre planteamientos y lógicas de desarrollo de diferentes políticas públicas que tendría su reflejo tanto en la conformación del conjunto de actores que las ponen en marcha, como en la dinámica turística de la zona. El texto se articula en dos bloques. En el primero, se realiza un repaso a nivel nacional del papel de los instrumentos de la política de desarrollo rural y la política turística en sus dimensiones turística y territorial, respectivamente. En el segundo, se investiga la articulación de las estrategias de fomento del turismo en el caso de estudio distinguiendo dos espacios de desarrollo diferentes: el de la cabecera comarcal, Albarracín, y el de su entorno, la Sierra. Para la consecución de este trabajo se han utilizado catorce entrevistas semiestructuradas realizadas en 2015 a los gerentes de las organizaciones implicadas.

\section{Turismo y desarrollo en el medio rural: estado de la cuestión}

\subsection{El turismo como estrategia de la Política de Desarrollo Rural Europea en España}

Las drásticas reformas en la orientación productiva del medio rural en Europa occidental tienen como consecuencia una progresiva dislocación entre el mundo rural y la actividad agraria que da origen a nuevas perspectivas de desarrollo, entre las que destacan las medidas de fomento del turismo. La OCDE considera la actividad turística como la alternativa más favorable por su efecto multiplicador en la economía rural (1990). A nivel europeo, las instancias comunitarias utilizan un doble enfoque a partir de los 90 para otorgar al turismo en medio rural un peso específico y una cierta continuidad dentro de su política: el enfoque agrario, el predominante, y el enfoque turístico (Blanco Herranz, 1996).

Todos los principales documentos preparativos a las reformas de la $\mathrm{PAC}^{3}$ plantean la idoneidad de la actividad turística para diversificar las estructuras productivas con el fin de minimizar su declive socioeconómico. El turismo rural constituiría el principal motor de desarrollo de las zonas rurales porque respondería a una demanda

Libro Verde para la Reforma de la PAC, 1986; El Futuro del Mundo Rural, 1988; Evolución y Futuro de la PAC, 1991; Declaración de Cork, 1996. 
real, contribuiría a la salvaguarda del patrimonio a la vez que serviría de activo económico, y crearía empleos complementarios y alternativos a la agricultura. Sin embargo, el discurso institucional, no ofrece una definición clara de la modalidad. El impulso comunitario incluye de forma generalizada el sector turístico como eje principal de desarrollo de las regiones rurales especialmente desde 1991 dentro de los Programas de Iniciativas Comunitarias LEADER ${ }^{4}$ que es donde más peso tiene: el $42 \%$ de toda la financiación en el marco de LEADER I en Europa se destina a proyectos turísticos (Blanco Herranz, 1996). El peso que adquiere en este instrumento se puede interpretar como la voluntad teórica de la UE de asegurarse una explotación asociativa de la riqueza turística y de financiarla en función de las necesidades, capacidades y expectativas de las poblaciones locales. Así, según la CE (1988), la asociación de los agentes locales es el cauce idóneo para aprovechar el potencial local del desarrollo turístico.

Aunque a finales de los años sesenta aparecen en España las primeras iniciativas de apoyo al turismo en medio rural (Molinero, 1994 en Cànoves et al., 2006), no es hasta principios de los 90 con el impulso comunitario producido por la reforma de los fondos estructurales y la adhesión de España a la entonces CEE cuando se integra el sector turístico como uno de los ejes principales de desarrollo de las zonas rurales. Desde 1991 se han sucedido cuatro periodos de programación y en todos ellos, aparecen líneas de financiación específicamente dirigidas al fomento del turismo rural y el agroturismo (IGN, 2008). En el caso de LEADER I la financiación española supera la cifra media europea de apoyo a proyectos turísticos alcanzando el $51 \%$ del total de los fondos. Se invirtieron en España 198 millones de euros en más de 2.300 acciones de las cuales un cuarto se dedicaron a la creación de alojamientos de turismo rural (ATR) (26,35\%), y en menor medida a la creación de oferta complementaria (16,77\% para ambos) y a la mejora de patrimonio y pueblos (8,57\%). Este sesgo sectorial no respondía tanto a una planificación de desarrollo ni a una política de revalorización del patrimonio como a las demandas de la población local y la iniciativa privada (Noguera et al, 1997 en Pitarch y Amandís, 2014: 324) en un contexto de altas expectativas creadas en torno al sector turístico en España.

LEADER II (1995-1999) se aplicó en España estableciendo un porcentaje máximo del 30\% por línea de actuación para corregir la inversión concentrada. Sin embargo, al finalizar el periodo, la "medida estrella" del turismo superaba el umbral mínimo establecido alcanzando casi un tercio de la financiación movilizada. Las actuaciones de creación de ATR se moderaron en favor de otras actuaciones como la realización de inventarios de recursos patrimoniales, estudios de mercado, creación de infraestructuras públicas y promoción. En este mismo periodo, en el programa

4 El instrumento LEADER tiene por objetivo desde 1991 la gestión local de la diversificación de la economía rural. Se trata del instrumento que materializa el modelo europeo de desarrollo rural endógeno, teóricamente más eficaz que los modelos anteriores de desarrollo conducidos desde la escala del poder central (Van der Ploeg et al., 2000). 
PRODER $1^{5}$, las medidas de fomento de pequeñas empresas y artesanía, y turismo concentraban casi la mitad de la inversión total realizada, siendo el turismo la tercera medida más financiada y manteniéndose la creación de ATR como la acción más común.

A partir de 2000 los territorios más veteranos constatan los problemas de rentabilidad generados por los ritmos impuestos por la estacionalidad de la actividad como en la Comunidad Valenciana (Pitarch \& Arnandís, 2014). Es por ello que con LEADER + se limita la financiación a aquellos ATR programados en zonas no saturadas turísticamente y que tengan un cierto grado de calidad y se pasa a promover las actividades complementarias y las infraestructuras de apoyo. Finalmente, a partir de 2007, el eje LEADER de la PAC, que se aplica al 89\% del territorio español, mantiene el apoyo a una medida independiente de fomento del turismo en la que se enmarcan acciones como la creación de infraestructuras de acogida de pequeña escala, señalización, alojamiento de capacidad reducida y comercialización de servicios turísticos. Para esta medida se han subvencionado hasta 2009, alrededor de 3.248 nuevas actividades 6 .

En líneas generales, el discurso institucional de fomento del turismo en medio rural corresponde a una filosofía, a un modelo teórico (y en cierta medida utópico) de desarrollo que dista de los efectos reales que la inserción de la actividad turística ha tenido en estos espacios por cuestiones derivadas de su proyección en el mercado turístico o de su escasa integración con el resto de actividades en estos espacios (Ivars, 2000). Sirva de ejemplo cómo en las últimas fases, los vínculos con la agricultura se han roto para emprender el camino marcado por la industria turística y no la actividad primaria pues solo el 1,6\% de las explotaciones agrarias están involucradas en esta actividad (Cànoves et al., 2004). A pesar de ello, la estrategia de diversificación económica del medio rural continúa pivotando en gran medida sobre el turismo, configurándose así una realidad en la que la totalidad de las comarcas rurales españolas han iniciado procesos más o menos ambiciosos de desarrollo turístico (Vázquez y Martín, 2011).

\subsection{Turismo rural y Política Turística en España}

La activación de destinos de turismo rural en España a partir de los años 90 enlaza directamente con la filosofía de los grandes Planes Turísticos del Estado (Plan Marco de Competitividad del Turismo Español I y II (FUTURES I y II, 1992-1995 y 19961999), Plan de Integral de Calidad del Turismo Español 2000-2006 (PICTE), Plan del Turismo Español Horizonte 2020 y Plan Nacional e Integral de Turismo 2012-

5 PRODER 1 nace a raíz de la exclusión de las regiones objetivo 1 de la aplicación de LEADER II. Para asegurar su aplicación en un máximo de territorio, el Ministerio de Agricultura, Pesca y Alimentación junto con las diez CC.AA. objetivo 1 crean este programa paralelo en cuya financiación participarán los fondos europeos.

6 Plan estratégico nacional de desarrollo rural elaborado por el MAGRAMA: última versión de mayo de 2012. Los datos sobre los indicadores de ejecución se refieren a 2009. 
2015. Al menos hasta el Plan Horizonte 2020 se venían planteando de forma explícita objetivos relacionados con la diversificación del producto turístico "España" (que pivotaba y sigue pivotando sobre el turismo de sol y playa). En líneas generales esta búsqueda de diversificación de la oferta se tradujo en un apoyo directo vía subvenciones a proyectos de desarrollo de destinos y productos relacionados con los "otros turismos", entre ellos el turismo rural, que aparece como un segmento importante de actuación en todos los Planes.

El PICTE (2000-2006) incluía el turismo rural al menos en dos programas, "Calidad en destinos turísticos”, con apoyo a los Planes de Dinamización Turística dirigidos a la activación económica y potenciación de destinos turísticos emergentes (los rurales entre ellos), y "Calidad en productos turísticos" que mencionaba entre sus objetivos: 1). La consolidación de las bases empresariales del turismo activo y de aventura y la regulación de su ejercicio para garantizar la calidad y la seguridad del consumidor y 2). La reorientación de los programas de ayudas al desarrollo del turismo rural y coordinación en lo referente a tipologías y calidad. En el Plan del Turismo Español Horizonte 2020, no encontramos una alusión directa al turismo rural, si bien en la programación 2008-2012, dentro del eje estratégico "Sostenibilidad del modelo" se definió un programa de desestacionalización y reequilibrio socioterritorial con el objetivo de "Revalorizar aquellos recursos que fomentasen la desestacionalización y el equilibrio socioterritorial del turismo, creando nuevas categorías de productos capaces de operar todo el año sobre la base de la diferenciación y especialización de los destinos turísticos”. En este ámbito los recursos y territorios rurales ocupaban un papel relevante y eran objeto de las líneas de actuación de este programa de productos basados en recursos turísticos experienciales y singulares, desarrollar acciones de interpretación, puesta en valor y en mercado del producto turístico o articular una oferta de servicios turísticos públicos y privados en torno a los argumentos temáticos prioritarios. En el actual Plan Nacional e Integral de Turismo (2012-2015) apenas aparecen referencias al turismo rural. No obstante encontramos al menos dos medidas relacionadas como son la "homogeneización de la clasificación y categorización de establecimientos rurales" y a la "puesta en valor del patrimonio cultural, natural y enogastronómico".

Pero de forma específica, en el año 2014 vio la luz el Plan Integral de Turismo Rural. En él el turismo rural se entiende "como la actividad turística en entorno rural o natural no masificado que contribuye al gran objetivo de calidad y diversificación del modelo turístico español”. Se argumenta que la articulación, promoción y comercialización de un producto de turismo rural de calidad contribuye a: a). Generar riqueza y dinamizar áreas geográficas con menor flujo turístico o económico y a la integración del territorio, b). Distribuir los flujos de demanda a lo largo de todo el año al realizarse los viajes fundamentalmente en fines de semana o en estancias tipo fly and drive para el turismo internacional y c). Diversificar las actividades económicas de determinadas zonas y a preservar las tradiciones del territorio sobre el que se fundamentan. (Instituto de Turismo de España 2014: 5). En conjunto este plan, si bien resulta demasiado escueto y genérico, estructura una serie de escasas propuestas en torno a la oferta (mejorar el sistema de clasificación de alojamientos rurales, fomentar 
trabajos de apoyo al desarrollo del Sistema de Calidad Turística en Destinos para el turismo activo y realizar actuaciones sobre el producto ecoturismo) y en torno a la demanda internacional (promoción y apoyo a la comercialización internacional de destinos y productos de turismo rural: presencia en internet y campañas de publicidad) . Del lado de la demanda, el plan sólo se centra en la captación de demanda extranjera con propósito de "adaptar la oferta turística a las exigencias de un nuevo entorno turístico internacional que demanda productos turísticos experienciales” (Instituto de Turismo de España 2014: 5).

Pero el apoyo directo de la política turística del Estado a la conformación planificada de destinos y productos en general (y de turismo rural en particular) ha venido impulsando en el marco de los sucesivos Programas de Planes en Destino que (con distinto nombre y encuadrados en diferentes ejes estratégicos) ha tenido continuidad a lo largo de estos veinte años de planificación estatal. En perspectiva diacrónica la aplicación de estos programas de planes en destino ha atravesado varias fases. Durante la primera fase (de 1998 a 2005) se aprueban los denominados Planes de Excelencia (PET) y Dinamización Turística (PDT); los primeros orientados a la regeneración y recuperación de destinos maduros y los segundos al impulso de destinos emergentes, entre ellos los del ámbito rural. En 2005 los PET y los PDT quedaron refundidos dentro de los Planes de Dinamización del Producto Turístico (PDPT), sobre el papel mucho más orientados a destinos en desarrollo y centrados fundamentalmente en la creación de productos directamente comercializables a partir de los recursos y empresas existentes. La tercera y última fase arranca en 2008 con la puesta en marcha de los denominados Planes de Competitividad Turística (PCT). Entre la lista de Planes en Destino aprobados entre 1992 y 2011 (www.planesturisticosendestino.es), y a pesar de las dificultades de adscripción, se podría considerar que hasta 114 (de 265) se han desarrollado en poblaciones y comarcas del ámbito rural (García Hernández, 2014).

En líneas generales los planes en destino han contribuido, al desarrollo de una nueva forma de intervenir en destino desde la óptica local que se extiende también al mundo rural, la de la planificación estratégica. Sin embargo, el repaso de los modelos de planes fraguados en las distintas generaciones de Planes en Destino evidencia cómo han ido variando las condiciones de los procesos de planificación turística en general, pero también en el mundo rural. El cambio más evidente afecta al enfoque de la planificación. Se ha pasado de un enfoque de planificación integral del destino a enfoques más orientados a la articulación y comercialización de productos específicos en torno a los cuales se crea o reorienta la oferta y el atractivo de los destinos. Los PEyDT tenían como objetivo la conformación del destino y se trabajaba con muchos ámbitos: adecuación oferta patrimonial y puesta en valor turística de recursos, actuaciones de mejora de la acogida al visitante, actuaciones de recuperación urbana en óptica turística, etc. Cuando se da el paso a los PDPT y especialmente a los PCT cambia el enfoque de intervención y, al menos sobre el papel, se tematiza la planificación en relación a ejes prioritarios que tienen que ver con la creación de productos. Ejemplifica muy bien ese cambio de enfoque las denominaciones de algunos de los últimos planes aprobados: “Águilas - El Mar y la Pesca" o "Bosques 
de Brujas y Bandoleros”. Sin embargo estos productos han venido teniendo un soporte territorial cada vez más difuso y discontinuo. De hecho los planes aprobados en los últimos años del programa muestran una tendencia a focalizar la atención sobre territorios cada vez más amplios con el fin de dar visibilidad y coherencia a actuaciones conjuntas que toman en consideración una escala de trabajo en la que se puedan superar los estrangulamientos y limitaciones de gestión de la débil administración local del medio rural. Es por ello que estos planes tienden a tomar como interlocutores a las diputaciones provinciales, a entidades ya consolidadas (comarcas o mancomunidades muy activas) o a otras entidades supralocales más potentes.

\subsection{Turismo rural: ¿una modalidad turística sostenible?}

El turismo en el medio rural es un fenómeno relativamente nuevo en España, que sin embargo es un país de larga tradición turística. Las iniciativas pioneras de turismo rural apenas se remontan a la década de los años 80, y es ya en los 90 cuando se generaliza el término, las prácticas y los usos, actualizando ofertas turísticas latentes que hasta entonces habían tenido unas demandas muy minoritarias en el país. Por ello a partir de ese momento, el crecimiento en términos de oferta y demanda fue significativo, con una fuerte difusión de la actividad turística sobre el espacio rural especialmente evidente en territorios de interior y en las áreas de montaña media (Cebrián, 2014). Sin otros datos que los relativos a la magnitud de la oferta y la demanda de alojamientos rurales (estimada en la Encuesta de Ocupación de Alojamientos de Turismo Rural del Instituto Nacional de Estadística) se observa cómo en los últimos 14 años la oferta de plazas de alojamiento turístico rural ha aumentado en un $230 \%$, mientras el número de viajeros alojados y pernoctaciones realizadas lo ha hecho en un 133\%. En 2001 había 42.925 plazas de alojamiento, 1.210.891 viajeros alojados y 3.660.815 pernoctaciones que se han convertido en 141.478 plazas, 2.822.947 viajeros y 7.750.576 pernoctaciones en 2014. En términos globales el balance resulta positivo, sin embargo las curvas de evolución muestran divergencias entre la siempre creciente oferta de plazas de alojamiento y los vaivenes de una demanda que se contrajo en los años más duros de la actual crisis económica, con un número de viajeros y pernoctaciones más o menos estancado desde 2007. En líneas generales presenta graves problemas estacionalidad y de rentabilidad. Dos meses (julio y agosto) concentraron en 2014 el 27\% de las llegadas de viajeros alojados en establecimientos con niveles medios de ocupación realmente bajos, 14,85\% para el mismo año (EOATR, INE 2015). Los problemas de estacionalidad y baja ocupación convergen además con una serie debilidades estructurales que inciden en la viabilidad de las iniciativas turísticas en espacios rurales: carencias y déficits de accesibilidad, bajas densidades de población, envejecimiento, escasez de efectivos humanos, débil cualificación profesional, etc.

No obstante la situación actual no es heterogénea, conviven iniciativas de éxito con situaciones de atonía en las que muchas de las actividades que surgieron en años de bonanza económica se han abandonado: equipamientos turísticos con falta de 
mantenimiento, alojamientos sin actividad la mayor parte del año, locales y empresas de actividades turísticas cerradas, etc. En líneas generales se dibujan dos realidades que corresponden a lógicas de comportamiento turístico diferentes: las que podríamos asociar al turismo rural genérico y aquellas otras vinculadas con el desarrollo de los “turismos rurales específicos". El turismo rural genérico es un turismo basado en el consumo de "campo" e incluiría las estancias y viajes recurrentes a la segunda residencia en el medio rural, el alojamiento en casas de turismo rural y la visita clásica a los espacios naturales protegidos. Por el contrario, los turismos rurales específicos serían aquellos relacionados con el consumo de productos turísticos en el campo. Espacios posicionados en el mercado en base a la articulación y desarrollo de productos de enoturismo, balnearios y termalismo o turismo deportivo, con ejemplos de destinos muy consolidados e iniciativas de capital y saber hacer foráneo bien conectadas con los mercados emisores de visitantes (García Hernández y Calle Vaquero, 2006; García Hernández 2014). El nivel de implicación con la realidad socioeconómica local del medio rural varía notablemente de un modelo de turismo rural al otro. De hecho, las políticas de desarrollo rural, desde cierto desconocimiento de la lógica de funcionamiento del sector turístico, han lanzado a multitud de comarcas hacia el desarrollo de un turismo rural genérico en el que existen fuertes dificultades de conexión con los mercados emisores y por tanto de captación y fidelización de la demanda. Frente a ello, los turismos rurales específicos, más recientes, se alejan de la filosofía de desarrollo territorial y buscan, en lógica sectorial y a partir de recursos exógenos, una rentabilidad económica que haga viable la explotación turística de determinados recursos e infraestructuras.

\section{El turismo en Albarracín y Comarca}

La Comarca de la Sierra de Albarracín ubicada en plenos Montes Universales se configura como un territorio cohesionado histórica y geográficamente. Con 5.000 habitantes y una densidad que ronda los $3,5 \mathrm{hab} / \mathrm{km}^{2}$, cuenta con veinticinco municipios muy afectados por históricos procesos de éxodo poblacional y crisis de las actividades agroganaderas y forestales tradicionales. El municipio de Albarracín con apenas 1.100 habitantes, es la cabecera comarcal y la primera ciudad de Aragón en ser declarada Monumento Histórico en 1961. Alberga un singular patrimonio cultural edificado de carácter civil y religioso construido en tres momentos históricos en los que adquirió cierta relevancia político-económica a nivel regional (siglos X-XII, XVI y XVIII) y que sufrió especialmente los destrozos causados durante la Guerra de la Independencia y la Guerra Civil. Además, posee importantes valores paisajísticos asociados al enclave natural donde se ubica el núcleo urbano, elevado sobre un meandro rocoso formado por el río Guadalaviar. Aunque en la comarca existen dos núcleos tradicionales de actividad turística, Albarracín y Bronchales, fue a partir de los años 90 cuando se generalizó su fomento desde las administraciones públicas por todo el territorio. 


\subsection{Instrumentos y agentes del desarrollo turístico de la Sierra de Albarracín}

La proliferación de instituciones, asociaciones y otros tipos de organizaciones a nivel local apoyadas por las propias políticas públicas, es muy notable. A partir de 1996 surgen dos agentes clave de la acción pública local en materia turística aunque con dos enfoques y cometidos diferentes: el Grupo de Acción Local (GAL) que gestiona el instrumento LEADER y la Fundación Santa María de Albarracín (FSM), fórmula de cooperación público-privada que gestiona la dinamización cultural del patrimonio. Con el proceso de comarcalización de Aragón a principios de los 2000, la Comunidad histórica, único ente supramunicipal presente en el territorio hasta entonces, pierde sus funciones en favor de la nueva comarca político-administrativa que asume importantes competencias en materia turística ${ }^{7}$. El panorama se completa con las asociaciones sectoriales principalmente del sector del alojamiento y agroalimentario que integran el GAL.

Figura 1. El casco urbano de Albarracín en su entorno.

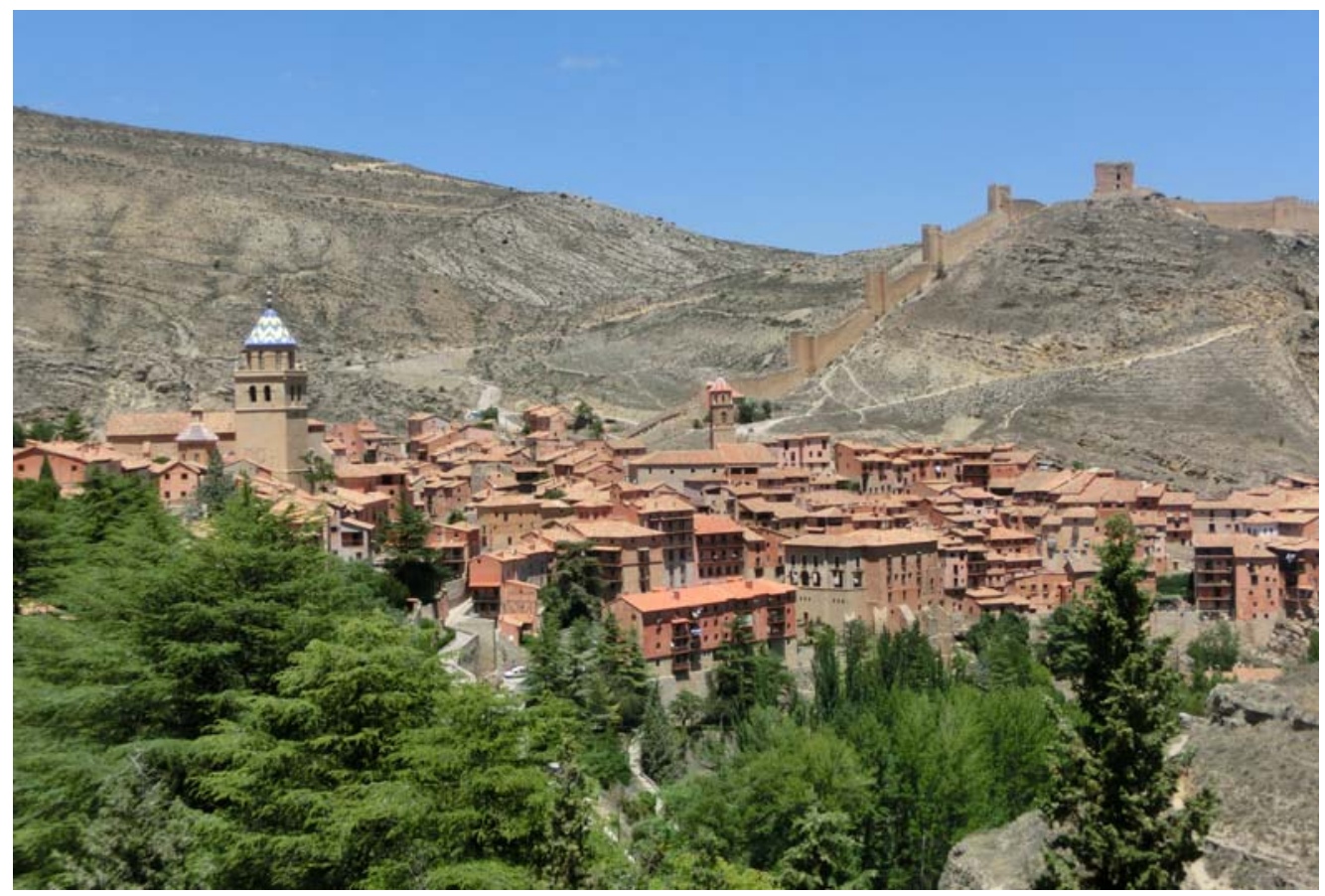

Fuente. Elaboración propia (2014).

El peso de la materia turística en la actuación de las nuevas comarcas de Aragón, se explica por el contexto de rápido crecimiento del sector turístico a principios del siglo XXI (López Jiménez, 2008). 
En consonancia con una aproximación evolutiva del impulso turístico, cabe afirmar que la disponibilidad de un importante número de edificios rehabilitados de alto valor patrimonial en Albarracín constituyó el impulso primero del desarrollo turístico en la comarca (Randelli, Romei, \& Tortora, 2014). Así pues y como ocurre en otras localidades (Martín, 1994), son las políticas de Patrimonio, Cultura y de Empleo las que dan comienzo a un largo proceso de rehabilitación y activación turística del conjunto histórico de Albarracín. El proceso de recuperación patrimonial acometido sobre el conjunto se origina en los años 50 y se prolonga, caracterizado por la continuidad en el tiempo de pequeñas inversiones, hasta la actualidad (Almagro et al., 2006) en tres fases: restauración de urgencia, dinamización socioprofesional y dinamización cultural. Ha dado forma a un paisaje de significativa monumentalidad que enlaza con los valores del entorno en el que se ubica (Figura1).

Durante la primera fase, las primeras restauraciones fueron llevadas a cabo por el organismo de Regiones Devastadas y las Direcciones Generales de Arquitectura y de Bellas Artes, tomando ésta última el relevo definitivo en los años 60 de modo que hasta los años 90, esta DG ejecuta más de la mitad de todas las intervenciones públicas en Albarracín. Con fuerte protagonismo de la iniciativa del profesor D. Martín Almagro Basch en 1961 se declara la ciudad como Monumento Histórico, lo que evitó que prosiguieran las demoliciones de edificios, las aperturas en el tejido urbano y varios grandes proyectos, ligados al desarrollo turístico prematuro (Almagro et al, ibíd.). Tras esta primera etapa de restauración y acondicionamiento de los principales monumentos y sus entornos (Catedral, murallas, Iglesia de Santiago, Iglesia de Santa María, así como de otros elementos de la arquitectura popular) se da paso a una nueva etapa marcada por la puesta en marcha de las Escuelas Taller para reorientar la actividad de rehabilitación hacia objetivos de superación de las altas tasas de desempleo juvenil que venía sufriendo la comarca. Gracias a la implementación de dos Escuelas (1988-1991 y 1992-1995) se acometieron alrededor de treinta actuaciones en algunos de los edificios más emblemáticos de la ciudad. La experiencia en materia técnica y de gestión, así como las relaciones profesionales de confianza establecidas sirvieron de base para constituir en 1996 la FSM para la dinamización de este patrimonio conformada en torno a 4 patronos: el ayuntamiento de Albarracín, el Obispado de Teruel y Albarracín, el Gobierno de Aragón y la entidad bancaria Ibercaja. Con este paso, la trayectoria de la intervención sobre el patrimonio cultural en Albarracín se desplaza hacia la activación cultural, dotando a la ciudad de una serie de espacios de intensa actividad cultural que se han convertido en potentes recursos turísticos. A través de cesiones, la FSM gestiona doce infraestructuras culturales ubicadas en edificios recuperados bajo su iniciativa. El Palacio Episcopal, por ejemplo acoge el Museo Diocesano, el Centro de Información y un espacio para Congresos. Gestiona también un Centro de Restauración y el auditorio de la Iglesia de Santa María. Además cuenta con tres residencias (Pintores, Santa María y la Julianeta), y cinco espacios visitables articulados en un mismo producto (Museo Diocesano, Museo de Albarracín, Castillo de la ciudad, Torre Blanca y Ermita de San Juan). De manera adicional, la FSM se involucra en la prestación de servicios turísticos (información, visitas guiadas, apoyo para la 
organización de reuniones o congresos,...). De esta forma, se convierte en el principal ente gestor de la oferta turística cultural de la ciudad de Albarracín ${ }^{8}$.

Como en la mayoría de casos, fue la disponibilidad de fondos para el desarrollo rural a partir de la iniciativa LEADER II (1996-1999) lo que generó tanto el tejido asociativo en la comarca como una creciente oferta turística. Así, integraban el GAL la Asociación de Empresarios Turísticos (AETSA) y la Asociación de Viviendas de Turismo Rural (AVTR). Durante el primer programa LEADER se favoreció el crecimiento de la oferta alojativa, además de financiando directamente estos proyectos, poniendo a disposición de nuevos pobladores la gestión de diversos recursos turísticos de propiedad pública. También sirvió de oficina turística comarcal e impulsó la creación y promoción de productos de carácter genérico como las rutas turísticas por la comarca y la edición de folletos. Las inversiones en turismo se ralentizaron a partir del siguiente programa LEADER + (2000-2006) a raíz de la toma de conciencia del apresurado aumento de la capacidad alojativa de la comarca. A pesar de ello, las últimas acciones financiadas en el sector turístico (2011-2013) reflejan el apoyo a la construcción de un hotel, unos apartamentos turísticos y una vivienda de turismo rural, un nuevo centro de interpretación, la señalización de rutas turísticas y varios acondicionamientos de áreas recreativas. En este último periodo de programación (2007-2013) existe una evolución de la estrategia hacia la complementariedad con el sector agroalimentario especialmente con la creación de un producto turístico especializado: las Jornadas micológicas (incluye unas rutas interpretativas para la recolección, exposiciones, talleres de cocina y degustación en los restaurantes adheridos ) que forman parte de un proyecto de mayor amplitud: la regulación y dinamización turística de un parque micológico en la Sierra de Albarracín. Aún incipiente, el proyecto se encuentra en fase de estabilización institucional, extensión espacial y exploración de su viabilidad económica.

En el ejercicio de sus competencias en planificación turística, la recién creada Comarca promueve la elaboración y ejecución de un Plan de Dinamización Turística (2004-2008) de escasa trascendencia que sirve, en realidad, para dar comienzo a la actividad de la Comarca: se crea oficialmente la oficina de información turística comarcal en Albarracín y el portal web de la institución, además de acometerse ciertas actuaciones en torno a la iluminación monumental, la señalización de senderos y la implementación de un modelo de calidad turística, actuaciones que han sido difíciles de mantener y de cumplir con las expectativas generadas. En la práctica actual, la Comarca canaliza ciertas ayudas para iniciativas de dimensiones y alcance reducidas que promueve junto a los agentes de la Sierra. Si para algunos la comarcalización debía servir de espacio territorial e institucional en torno al cual desarrollar un proyecto turístico consensuado, en la Sierra no ha tenido suficiente

8 Sobre el proceso de recuperación patrimonial durante las Escuelas Taller y, especialmente, de dinamización cultural del patrimonio de la FSM ver Yubero y García, 2014. 
arraigo, a pesar de que se ha tratado de instaurar un Consejo Sectorial de Turismo como espacio de participación comarcal.

Por último, son los instrumentos de la política autonómica de patrimonio natural y cultural los que mayor influencia tienen en la creación de la oferta turística planificada de la comarca. Existen dos áreas protegidas que cuentan con legislación específica y órganos gestores propios que dependen del Gobierno de Aragón: el Parque Cultural de Albarracín y el Paisaje Protegido Pinares de Rodeno. Ambas figuras se fundamentan en la existencia de, entre otros, las pinturas y abrigos rupestres que forman parte del conjunto de Arte Rupestre de Arco Mediterráneo declarado Patrimonio de la Humanidad por la UNESCO en 1998. En el área se han construido 6 equipamientos turísticos de información e interpretación, 4 áreas recreativas, alrededor de $120 \mathrm{~km}$ de senderos, 38 aparcamientos con una capacidad de 2.300 personas/día, un observatorio de avifauna y 9 miradores. Sus perímetros de protección se encuentran solapados en una parte del área de modo que además de la profusión de equipamientos existe una señalización desestructurada y confusa. El grado de dinamización turística de estas áreas depende directamente de la capacidad técnica y financiera de estos espacios, mayor en el Paisaje Protegido que en el Parque Cultural.

La acción pública local está marcada por una estructura particular si atendemos a las alianzas establecidas en el despliegue de la dinamización turística del territorio comarcal. Con los datos recogidos sobre el intercambio de recursos en la materia (financiación, ayuda para la promoción, implicación en la creación conjunta de un producto específico, incluso miembros que participan en varias entidades...) observamos que existe una polarización de las relaciones en torno a algunos agentes de ámbito supralocal como son la Comarca y los agentes asociados a LEADER (el GAL y las asociaciones participantes AETSA, AVTR y AAASA). Por otro lado, destaca la prácticamente ausente relación entre, primero, este núcleo y los agentes del Paisaje Protegido y del Parque Cultural y, segundo, entre el mismo núcleo y la FSM. Éste es el resultado de las alianzas fraguadas en un contexto de pérdida de capacidad técnica y financiera como ocurre en la mayor parte del medio rural español (Martín y Martín, 2014). La influencia de la estructura de los agentes en el desarrollo de la política turística local como señalan algunos estudios (Hall, 2011) indicaría que este despliegue de la acción pública turística de carácter fragmentado constituye una de las causas de la variable implementación de la estrategia turística dando lugar, recientemente, a una doble dinámica del desarrollo turístico que se presenta a continuación.

\subsection{Desarrollo turístico reciente}

El municipio de Albarracín, y en menor medida y por contagio la Comarca de la Sierra de Albarracín, se configuran como focos de actividad turística. En 2015 Albarracín municipio contaba con 36 establecimientos de alojamiento, 911 plazas (que se elevan hasta 1.221 si se contabilizan las parcelas del camping), 27 bares y restaurantes, más de 1.200 plazas de restauración y 2 empresas de turismo activo. Son 
datos muy elevados para un municipio de apenas mil habitantes, pero también lo son los datos de la comarca: 98 establecimientos alojativos con 1.238 plazas, 32 restaurantes con 1.420 plazas y 6 empresas de turismo activo. En conjunto, pues, 134 establecimientos de alojamiento con más de 2.200 plazas, datos que dan idea de la importancia de la actividad turística en la zona. Algo más inciertos son los escasos datos disponibles relativos a la demanda, que además se circunscriben al municipio de Albarracín (año 2014): alrededor de 120.000 consultas anuales en la Oficina de Información Turística comarcal, 38.300 viajeros alojados en los establecimientos hoteleros (año 2014), baja proporción de visitante extranjero $(8,4 \%)$ y estancia media inferior a dos noches (1,6 noches/viajero). No obstante, más allá de los datos numéricos, la interpretación de la realidad turística de la zona evidencia la coexistencia de dos modelos turísticos diferenciados: uno para la ciudad de Albarracín, destino consolidado de turismo cultural de base patrimonial, y otro para la Comarca, que se configura como un destino incipiente de turismo rural y deportivo. Ambos modelos tiene dinámicas propias y notables diferencias que se manifiestan, al menos, en tres de los factores que recogen las principales teorías del desarrollo del turismo rural (Streimikiene y Bilan, 2015): en relación al atractivo turístico (patrimonio cultural monumental en Albarracín y paisaje y patrimonio natural en la comarca), en relación a la oferta turística (programación cultural del Albarracín frente a oferta de turismo activo en la comarca) y también en relación a las políticas e instrumentos de activación del atractivo turístico de ambos lugares (políticas culturales y de empleo en el caso de Albarracín y política de desarrollo rural en el caso de la comarca).

El municipio de Albarracín se configura como un destino de turismo patrimonial en el mundo rural muy consolidado para el turismo interno del país, al mismo nivel que otros referentes clásicos como la villa de Santillana del Mar (en Santander), La Alberca (en la provincia de Salamanca) o Chinchón (en la Comunidad de Madrid). Al igual que en estos lugares, la potencia del patrimonio histórico-cultural constituye la base de un acelerado proceso de desarrollo turístico, que en este caso arranca hace medio siglo, pero que resulta especialmente evidente en los últimos años. Además el patrimonio recuperado sirve de equipamiento para la organización de diverso tipo (cursos, conciertos, seminarios, exposiciones y estancias creativas) que han llegado a configurar flujos de turismo de motivación estrictamente cultural muy minoritarios, aunque continuos. Desde 1996 hasta la fecha la FSM ha organizado más de 1.600 actividades en las que han participado más de 90.000 personas (una media de 100 actividades y 5.000 participantes anuales) (Fundación Santa María, 2014). Se trata de una actividad cultural de gran proyección muy difícil de encontrar en otros municipios rurales españoles de tamaño poblacional similar. El atractivo turístico del patrimonio adecuado para la visita (Museo de la Ciudad, Catedral y Palacio Episcopal,...) y la iniciativa turístico-cultural de la propia FSM (con su programa de visitas guiadas y actividades culturales) convergen además con una incipiente iniciativa privada que ha generado una oferta expositiva de mucha menor entidad.

En líneas generales, la recuperación patrimonial de Albarracín y su activación cultural han ido paralelas al crecimiento de los flujos de visita y la expansión de la 
iniciativa turística privada, base de su dinamización económica reciente. Entre el año 2000 y 2005 las actividades de restauración y bares, por ejemplo, experimentaron un crecimiento del 38\% (Alonso Hierro y Martín Fernández, 2008). Por su parte la oferta de alojamiento turístico reglado privado ha crecido entre 1994 y 2015 en 28 establecimientos y 532 plazas, multiplicándose por dos el número de plazas en veinte años. El crecimiento de la actividad turística se extiende también a las empresas de receptivo y el comercio turístico; están abiertos hasta 15 comercios que viven en mayor o menor medida del turismo (recuerdos, artesanía, alimentación y productos de escalada deportiva).

Frente a esta dinámica positiva de la oferta turística, el comportamiento de los flujos de visitantes no muestra una tendencia expansiva tan clara y continuada en el tiempo. La curva evolutiva de la demanda de alojamiento hotelero por ejemplo sigue los vaivenes causados por el retroceso del consumo turístico interno durante los años de la crisis económica (ver Gráfico 1 con datos relativos a 2003).

Gráfico 1. Evolución de la oferta y la demanda de alojamiento turístico en Albarracín (en \% para 2003=100).

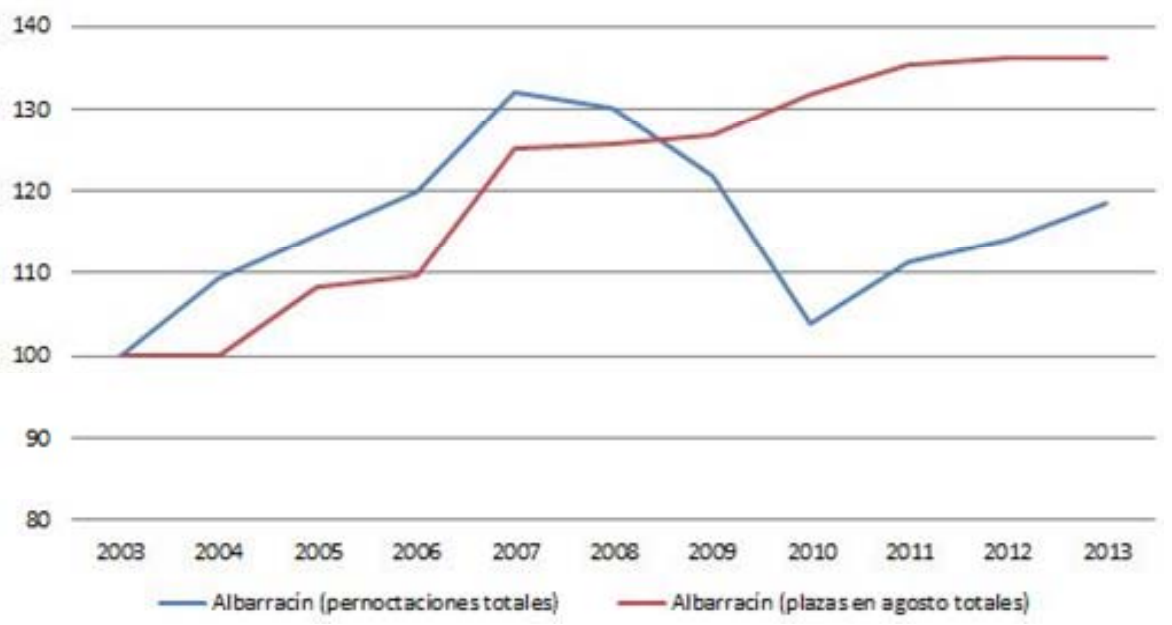

Fuente: Encuesta de Ocupación Hotelera (INE) y Guía de Servicios Turísticos (Comarca de Albarracín).

El número de viajeros alojados en hoteles entre 2005 y 2014 ha alcanzado máximos totales en 2007 (39.391) y mínimos en 2010 (28.903). El último dato de 2014 es de 38.298 viajeros y 64.833 pernoctaciones realizadas (INE, vvaa). A pesar de la escasa información disponible es posible observar dos constantes. En primer lugar la acusada estacionalidad en la llegada de visitantes a Albarracín (con un máximo muy acusado en verano y máximos secundarios en primavera y otoño relacionados con picos de máxima afluencia en fines de semana, puentes y periodos festivos cortos) (ver Gráfico 2). Y en segundo lugar el predominio del turismo nacional, que supone el $91 \%$ de los viajeros alojados y representa el $94 \%$ de las 
consultas atendidas en la Oficina de Información Turística. Los principales mercados emisores de visitantes a Albarracín son mercados de proximidad relativa (Valencia y Aragón), y CCAA muy pobladas de las que parten los flujos más mayoritarios de turismo interno en España (Madrid y Cataluña). Los extranjeros son aún minoritarios, pero presentan tasas de crecimiento interesantes: $+50 \%$ de las consultas de la OIT entre 2008 y 2014 y $+70 \%$ de viajeros alojados en hoteles en el mismo periodo, mostrando así un comportamiento ajeno a la crisis.

Gráfico 2. Distribución mensual de las pernoctaciones en 2014 en Albarracín.

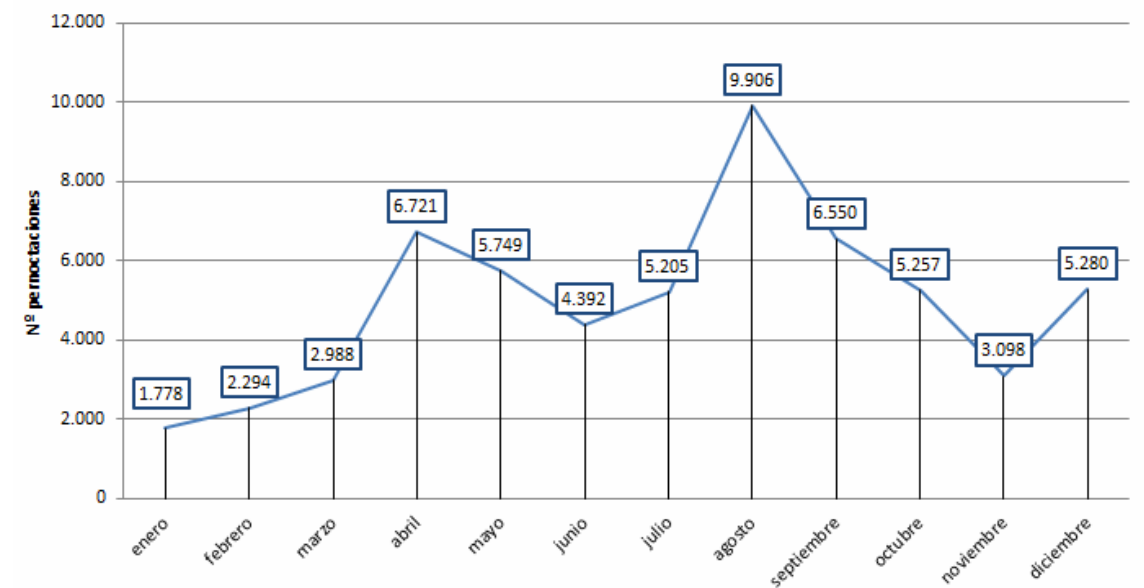

Fuente: Encuesta de Ocupación Hotelera (INE). Elaboración propia.

La relación entre oferta turística y número de residentes en el municipio arroja unos índices de especialización turística altísimos. A nivel global el número de establecimientos vinculados con la actividad turística (hostelería, receptivo, comercio turístico) supone el 82\% del total de establecimientos de actividad económica del casco urbano. Pero además con 1.059 habitantes en 2015 y 1.221 plazas de alojamiento, Albarracín tiene una relación de 1,15 plazas por habitante. En conjunto tiene capacidad para acoger 427.415 pernoctaciones anuales. En este contexto es frecuente que se presente Albarracín como un caso paradigmático de la estrecha relación entre la conservación del patrimonio histórico y la valorización socioeconómica asociada al desarrollo turístico. Alonso y Martín (2008) estimaban que el consumo turístico de todos los visitantes en 2004 venía a representar aproximadamente el $17 \%$ del Valor Añadido Bruto (VAB) de la comarca. No obstante el municipio enfrenta retos no desdeñables relacionados con la gestión de un desarrollo turístico tan potente. En principio, el volumen actual de pernoctaciones en el municipio supone tan sólo el $20 \%$ de esa capacidad alojativa total anual, lo que indica cierta situación de sofreoferta en un contexto creciente competencia turística 
con el municipio de Teruel. De hecho comienza a observase cierto efecto de inversión en el sentido de los flujos de visita aumentando el excursionismo en Albarracín con origen (pernoctación) en Teruel. Fenómeno muy reciente que está relacionado con el desarrollo del turismo en la capital de provincia. Teruel ha crecido mucho en número de visitantes y oferta hotelera en los últimos años, apoyándose en la puesta en marcha de iniciativas culturales de distinto calado como son Dinópolis o la asociación de los Amantes de Teruel (Sarasa, 2015). Entre 2003 y 2014 el número de viajeros alojados en los hoteles de Teruel creció un 55\% (INE). Por otra parte, y aunque las cifras globales de afluencia no parecen muy elevadas en relación con la capacidad actual de la oferta, la concentración de llegadas en momentos puntuales plantea ya problemas de sobrecarga y saturación turística. Esto es especialmente significativo respecto a la gestión del aparcamiento y la movilidad. Actualmente el casco urbano cuenta con 606 plazas de aparcamiento señalizado en superficie, pero la afluencia de visitantes en días punta desborda ya esta capacidad de aparcamiento, que no puede crecer mucho más porque el tamaño del viario imposibilitaría la movilidad rodada de acceso y rotación en esos espacios colapsando la circulación rodada, ya de por sí complicada.

Ahora bien, la potencia del municipio de Albarracín como destino turístico contrasta con el incipiente desarrollo de la Comarca de la Sierra de Albarracín. Este espacio, aunque no cuenta con patrimonio de dimensión monumental, atesora una serie de valores paisajísticos y ambientales que conforman la base de un incipiente atractivo turístico. En la Sierra adquieren carta de protagonismo como recursos turísticos el paisaje (Pinares de Rodeno, roquedos, saltos de agua como la Cascada de Calomarde, etc), elementos del patrimonio rural (acueducto de Gea) o los abrigos con arte rupestre del Parque Cultural de Albarracín. En torno a ellos se ha intentado configurar una oferta turística que pivota sobre equipamientos vinculados con la iniciativa pública (políticas de desarrollo rural) y algunas iniciativas privadas (vinculadas con el sector del alojamiento y algunas empresas de turismo activo). En líneas generales la comarca está hiperseñalizada, hiperacondicionada (merenderos, rutas de senderismo, fuentes, áreas recreativas....) y también sobredotada de centros de interpretación y otros espacios expositivos (de los que hay ocho en todo el territorio casi todos cerrados en la actualidad o con problemas de mantenimiento). La iniciativa de los múltiples agentes que intervienen en la comarca (ENP de Pinares, Parque Cultural, GAL,...) viene siendo responsable de las actividades de dinamización turística con iniciativas de distinto calado y alcance (Jornadas Micológicas, Programa Pedagógico del Parque Cultural, etc).

Los datos de oferta, ya señalados ut supra resultan en términos absolutos muy elevados: los 98 establecimientos de alojamiento albergan una capacidad de casi medio millón de pernoctaciones anuales. Dentro de la oferta de alojamiento el mayor número de plazas se ofertan dentro de la tipología de "viviendas de turismo rural" (35\%) seguido de hostales y de hoteles. A nivel territorial, destaca como 23 de los 25 municipios de la comarca cuentan con oferta de hostelería. Llama la atención el caso de Bronchales, que alberga una gran oferta alojativa por su tradición turística ligada a las recomendaciones de un médico valenciano en los años 60 de la idoneidad del aire respirado en los pinares. 
En relación a la dinámica turística reciente las dificultades de recopilación exhaustiva de datos imposibilitan ir más allá de las tendencias percibidas por agentes y población local. No hay datos de demanda desagregados a nivel comarcal y el funcionamiento intermitente de algunos servicios no permite obtener información relevante. No obstante, los agentes locales consideran que el 30\% de los visitantes que pasan por la OIT de Albarracín visitan otros puntos de la comarca, lo que situaría el flujo anual en torno a las 30.000 personas anuales. Por otra parte, tomado como referencia los datos relativos a la demanda de alojamiento de turismo rural de la provincia, se puede ponderar en unas 15.000 las pernoctaciones realizadas en 2014 en las viviendas de turismo rural de la comarca (que tiene un total de 470 plazas en esta modalidad). Por último, cabe reseñar el continuado decrecimiento del grado de ocupación a nivel provincial (ver Gráfico 3).

Gráfico 3. Evolución del grado de ocupación en los ATR (\%) de la provincia de Teruel (20042014).

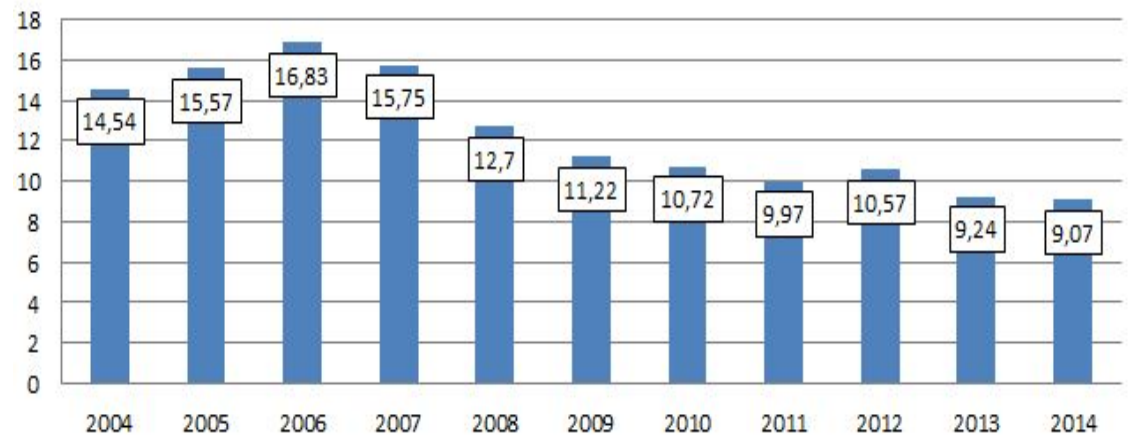

Fuente: Encuesta de Ocupación de Alojamiento de Turismo Rural (INE). Elaboración propia.

En líneas generales para el conjunto de la Sierra de Albarracín el balance del desarrollo turístico presenta luces y sombras. Ha habido gran desarrollo de la oferta turística privada de alojamiento y restauración, sin embargo la comarca se ha topado con las dificultades inherentes al desarrollo turístico del medio rural (despoblamiento, diseminación de recursos, falta de demanda agregada de proximidad, estacionalidad de la demanda,...). Además hay problemas de funcionamiento de equipamientos turísticos (claramente infrautilizados) en un contexto de profusión de iniciativas públicas y privadas de oferta expositiva e interpretativa. Equipamientos que es necesario mantener en la actualidad con menos recursos y ayudas públicas. Por otra parte el arranque de empresas de servicios turísticos ha sido tímido y se enfrentan a problemas para mantener un nivel de actividad rentable. Y finalmente aparecen también los problemas recurrentes de falta de demanda sostenida y baja ocupación de los alojamientos de turismo rural, que han sufrido especialmente con la contracción de la demanda interna durante estos años de crisis económica. 


\section{Discusión y conclusiones}

A pesar de la convergencia a escala local de los instrumentos de la Política de Desarrollo Rural y de la Política Turística que apuestan por el turismo como vector de desarrollo para el mundo rural, se han identificado matices divergentes en sus discursos y una separación entre éstos y la viabilidad real del desarrollo turístico tomando como ejemplo el caso de la Comarca de la Sierra de Albarracín. Ante las tendencias recientes y continuadas de crecimiento de la oferta turística en toda la comarca urgía una revisión de la dinámica del desarrollo turístico en el marco de las tendencias generales actuales. A nivel país las actuaciones acometidas han tenido un impacto muy heterogéneo sobre el desarrollo del turismo. El impulso público y el crecimiento de la demanda han configurado un mosaico de territorios con situaciones extremadamente dispares: desde zonas o comarcas muy asentadas turísticamente (relativamente pocas) a ámbitos de dudosa viabilidad turística. Además en este contexto, el retroceso de la demanda turística interna durante los años más fuerte de la crisis ha venido a plantear problemas de viabilidad para un gran número de las iniciativas de desarrollo turístico en ámbito rural.

Los planteamientos generales respecto al entendimiento del papel o del funcionamiento del turismo en el mundo rural varían de unas políticas a otras. De hecho en la lectura que del turismo rural hace la Política Turística encontramos una orientación que se ha ido alejando de los planteamientos contenidos en las políticas de Desarrollo Rural. En España, el discurso general de la Política Turística del Estado ha pasado de enfoques de actuación territoriales (que enlazaban con la lógica del desarrollo local) a una lógica de mercado de perspectiva más sectorial que supedita el desarrollo territorial a los objetivos generales de diversificación del producto turístico español. En otras palabras: de la conformación y dinamización de destinos turísticos (territorios comarcales más o menos amplios) a la articulación y desarrollo de productos turísticos concretos y viables en el mercado turístico. Para la Política de Desarrollo Rural, en cambio, el turismo continúa planteándose en base a modelos asistencialistas que lo conciben como un vector de complementariedad de rentas, pero con cierto desconocimiento de la lógica de funcionamiento del sector. De hecho, el éxito con que aparece el turismo como estrategia para el medio rural español se ha venido justificando por la disponibilidad de recursos públicos así como por las expectativas generadas en torno a las potencialidades de esta actividad como instrumento para la generación de rentes y empleo (Vázquez y Martín, 2011); una especie de panacea del desarrollo en las zonas rurales deprimidas (Cànoves, Villarino y Herrera, 2006). No obstante el seguimiento de la dinámica turística del medio rural (Fuentes García, vvaa) evidencia la existencia de unos problemas estructurales que lastran el desarrollo del turismo y que permanecen con el paso de los años independientemente del contexto turístico y económico general (excesiva dependencia de la demanda nacional, graves problemas de estacionalidad, baja rentabilidad de los establecimientos de alojamiento, escaso desarrollo de una oferta complementaria de actividades turístico-recreativas o falta de formación de los prestadores de servicios). En realidad, los problemas de viabilidad económica de la 
actividad turística en determinados espacios rurales ponen de manifiesto las limitaciones de una modalidad turística muy intervenida a partir del apoyo público de las políticas de desarrollo rural pero también muy promocionada e incentivada desde la política sectorial turística.

En la comarca objeto de estudio, la Política Turística no ha tenido prácticamente incidencia, pues ha sido subsidiaria de intereses institucionales. La Política de Desarrollo Rural ha tenido más continuidad en el tiempo y ha servido para crear un turismo rural genérico de escala comarcal excesivamente centrado en la creación de una oferta alojativa y de restauración que en momentos actuales de contracción de la demanda pasa por serias dificultades de supervivencia. En cambio, el destino "Albarracín ciudad" se consolida como destino maduro de turismo cultural apoyado por las actuaciones de rehabilitación patrimonial y de dinamización cultural al margen del resto de instrumentos. El éxito turístico de la cabecera comarcal contrasta pues con la atonía del desarrollo del resto de los núcleos de población. La cuestión escalar (Prats, 2011) nos muestra cómo la activación turística del patrimonio de Albarracín ha constituido un revulsivo para la actividad económica local, mientras que la activación turística del patrimonio de la Sierra encuentra serias dificultades. El impulso de las alianzas en torno al producto micológico constituye un ejemplo de cómo los esfuerzos están ahora centrados en la articulación de un producto específico en línea con el discurso estratégico que la Política Turística ofrece al medio rural.

Es preciso tener en cuenta que la activación turística de toda la Sierra pasa por la complementariedad entre el conjunto histórico de la ciudad de Albarracín y su entorno comarcal. Ante el riesgo de aumento de los impactos generados por una afluencia masiva puntual en el conjunto de Albarracín, se abre el camino para la articulación de una oferta que incorporase nuevas dimensiones del patrimonio (naturaleza, paisaje), que aprovechase el saber hacer generado en los últimos años y se proyectase en óptica participativa hacia el resto de la zona. No obstante, la observación de la estructura de las relaciones entre las organizaciones demuestra que apenas hay interrelación entre aquellas que operan en Albarracín y aquellas que lo hacen a nivel comarcal. En este nivel, las dificultades de coordinación y relación existentes entre la multitud de actores explicarían en parte las diferencias de velocidad en el desarrollo turístico y las ineficiencias del modelo comarcal. Esta estructura se plantea problemática para la planificación del desarrollo turístico. Una estrategia turística así planteada no puede acaparar la totalidad de la estrategia de desarrollo comarcal pero sí podría ofrecer un camino de mejora para la gestión turística del destino más acorde con su realidad.

En términos de investigación, el trabajo realizado necesita en fases posteriores incorporar una perspectiva comparada que sitúe este estudio de caso en un contexto más amplio que valide conclusiones generales sobre la situación de "desencuentro" entre políticas de desarrollo rural y política turística en espacios rurales y conclusiones particulares sobre la articulación institucional del desarrollo turístico a escala local. 


\section{Bibliografía y fuentes de información}

Almagro, A.; Jiménez, A. y Ponce de León, P. (2005): Albarracín. El proceso de restauración de su patrimonio histórico. Zaragoza, Fundación Santa María de Albarracín.

Alonso Hierro, J. y Martín Fernández, J. (2008): Conservación del patrimonio histórico en España. Análisis económico. Col. Estudios de Patrimonio, nº 1, Madrid, Fundación Caja Madrid, 59-78.

Blanco Herranz, F. (1996): Fundamentos de la política comunitaria y española en turismo rural. Estudios Turísticos,131, 25-49.

Cànoves, G., Villarino, M., y Herrera, L. (2006). Políticas Públicas, Turismo Rural y Sostenibilidad: Difícil equilibrio. Boletín de la A.G.E., 41, 199-217.

Cànoves, G., Villarino, M., Priestley, G., y Blanco, A. (2004): Rural Tourism in Spain: an analysis of recent evolution. Geoforum, 35, 755-769.

Cebrián Abellán, F. (2014): Turismo rural y de naturaleza. En Garcia Sánchez, A. (coord.): 20 años de la actividad turística en España. Madrid, Síntesis, 107-123.

Comisión de las Comunidades Europeas (1990): Medidas comunitarias para el fomento del turismo rural. COM (90) 438 final de 29.10.1990. Bruselas.

Fuentes García, R. (1995): El turismo rural en España. Especial referencia al análisis de la demanda. Ministerio de Comercio y Turismo, Secretaría General de Turismo. Madrid.

Fuentes García, R. (vvaa): Turismo en áreas rurales. En Asociación de Expertos Científicos en Turismo (ed): La actividad turística española en 1999... 2014. http://aecit.org/ediciones/pages/28/

Fundación Santa María (2014): Programación cultural y memoria de actividades 2014.

García Hernández, M. (2014): Nuevos lugares y produtos turísticos. En López Palomeque, F y Cánnoves Valiente, G. (eds.): Turismo y territorio. Innovación, reinvención y desafios. Valencia. Tirant Humanidades, 333-359.

García Hernández, M y Calle Vaquero, M. de la (2006): Turismo en el medio rural: conformación y evolución de un sector productivo en plena transformación. El caso del Valle del Tiétar (Ávila). Cuadernos de Turismo, 17, 77-103.

Grupo Sociológico de Investigación Científica de la Universidad de Zaragoza (2006). Las comarcas: una nueva organización territorial de Aragón. Disponible en línea en www.comarcas.es/pub/documentos/documentos_Comarcas.Nueva_organizacion_territoria 1_de_Aragon._03_Cultura_04df56b1.pdf

Hall, M.C. (2011): A typology of governance and its implications for tourism policy analysis. Journal of Sustainable Tourism, 19, $\mathrm{n}^{\circ} 4-5$, 437-457.

Instituto de Estudios Turísticos (2015): FRONTUR.

Instituto de Turismo de España (2014). Plan Integral de Turismo Rural 2014.

www.tourspain.es/es-

es/VDE/Documentos\%20Turismo\%20Rural\%202014/Plan\%20Integral\%20de\%20Turismo\%2 0Rural\%202014.pdf

Instituto Geográfico Nacional (2008): Atlas Nacional de España: Turismo en Espacios Rurales y Naturales.

Instituto Geográfico Nacional (2008): Atlas Nacional de España: Turismo en Espacios Rurales y Naturales. 
Istituto Nacional de Estadística (vvaa): Encuesta de Ocupación de Alojamientos de Turismo Rural. www.ine.es

Istituto Nacional de Estadística (vvaa): Encuesta de Ocupación Hotelera. www.ine.es

Ivars Baidal, J.A. (2000): Turismo y espacios rurales: conceptos, filosofías y realidades. Investigaciones Geográficas, 23, 59-88.

Jiménez Martínez A. (2005): Fundación Santa María: Un modelo de gestión cultural del patrimonio. Rehalda, CECAL, 1, 25-35.

López Palomeque, F. (2008): Delimitación conceptual y tipologías de turismo rural. En Pulido Fernández, J.I. (coord.): El turismo rural. Madrid, Síntesis, 21-74.

Martín Gil, F. (1994). Nuevas formas de turismo en los espacios rurales españoles. Estudios Turísticos, 122, 15-39.

Martín Gil, F. y Martín Hernanz, I. (2014): Los espacio rurales españoles: ¿territorios donde se produce y consume turismo o destinos sostenibles en entornos competitivos? El caso del nordeste segoviano. Boletín de la A.G.E., 64, 201-226.

OCDE (1990): Nuevas tendencias en política rural. Madrid MOPU-ITUR.

Pitarch, M., y Arnandís, R. (2014): Impacto en el sector turístico de las políticas de desarrollo rural en la Comunidad Valenciana (1991-2013). Documents d'Anàlisi Geogràfica, 60 (2), 315-348.

Prats, LL. (2011): La viabilidad turística del patrimonio. Pasos, 9 (2), 249-264.

Randelli, F., Romei, P., y Tortora, M. (2014). An evolutionary approach to the study of rural tourism: The case of Tuscany. Land Use Policy, 38, 276-281.

Sarasa, J. (2015): Mito y estrategias para un destino romántico: la ciudad de Teruel. Cuadernos de Turismo, 36, 39-54.

Secretaría de Estado de Turismo (2012): Plan Nacional e Integral de Turismo 2012-2015. Madrid, Ministerio de Industria, Energía y Turismo.

Secretaría General de Turismo (2007): Plan del Turismo Español Horizonte 2020. Madrid, Ministerio de Industria, Comercio y Turismo.

Secretaría General de Turismo (2000): Plan Integral de Calidad del Turismo Español: PICTE 2000-2006. Madrid, Ministerio de Economía.

Secretaría General de Turismo (1992): Turismo Rural. Plan de formación técnica en turismo rural. Volumen 3: Manual del Planificador. Madrid, Secretaría General de Turismo. THR.

Streimikiene, D., y Bilan, Y. (2015). Review of rural tourism development theories. Transformations in Business \& Economics, 14 (2), 21-34.

Van der Ploeg, J.D. et al., (2000): From Practices and Policies Towrads Theory. Sociologia Ruralis, 40(4), 391-408.

Vázquez Varela, C., y Martín Gil, F. (2011): Problemas de sostenibilidad del turismo rural de España. Anales de Geografía, 31(1), 171-194.

Yubero c. y García hernández M. (2014). La conservación activa del patrimonio cultural en medio rural como motor de desarrollo. El caso del conjunto histórico de Albarracín (Teruel). Actas del VII CIOT, FUNDICOT, 646-663. 